\title{
Associated Persons Exposure Domain
}

National Cancer Institute

\section{Source}

National Cancer Institute. Associated Persons Exposure Domain. NCI Thesaurus. Code C147171.

A domain utilized for the submission of exposure records related to persons associated with the study subject. 